\title{
15 MARKET OF RESOURCES AS AN ENABLER OF (INTER-)ORGANIZATIONAL RECONFIGURATION DYNAMICS
}

\author{
Maria Manuela Cunha \\ Polytecnic Institute of Cávado and Ave, Higher School of Technology, Portugal \\ mcunha@ipca.pt \\ Goran D. Putnik \\ University of Minho, School of Engineering, Portugal \\ putnikgd@dps.uminho.pt
}

\begin{abstract}
The Virtual Enterprise model is an emerging approach to answer to the new requirements of the business environment, relying on dynamically reconfigurable partnerships, with extremely high performances, strongly timeoriented while highly focused on cost and quality, in permanent alignment with the market, and strongly supported by information and communication technology, dictating a paradigm shift face to the traditional organizational models. Reconfiguration dynamics is a main characteristic of this model, which claims for supporting environments implementing a set of finctionalities. Some existing technologies can partially support this organizational model, but the reconfiguration dynamics can only by assured by an environment able to managing, controlling and enabling networking and dynamics in virtual enterprise creation/ reconfiguration. The Market of Resources is an environment coping with these requirements. The paper presents and discusses its validity in terms of improving the potential inter-organizational reconfiguration dynamics.
\end{abstract}

\section{INTRODUCTION}

Enterprises are no longer confined to its four walls, and the networked value chain concept is extending to several organizational approaches, with extremely high performances, strongly time-oriented while highly focused on cost and quality, and permanently aligned with business opportunities, to answer to the new requirements of the business environment. Some of these approaches rely on dynamically reconfigurable partnerships in permanent alignment with the market, and strongly supported by information and communication technology, dictating a paradigm shift face to the traditional organizational models. The leading organizational model incorporating these characteristics is the Virtual Enterprise (VE) organizational model, characterized as a dynamic organizational model. 
The implementation of the VE model should assure the required reconfiguration dynamics, which as we will see in the paper is dependent of (1) the reduction of reconfiguration costs and effort, i.e., requires a balancing between reconfiguration dynamics and reconfiguration time and costs and (2) the capability to preserve the firms' private knowledge on products or processes.

In the paper we discuss the VE reconfigurability requirement and the requirements of reconfiguration dynamics, introduce some environments to cope with these requirements and introduce the Market of Resources as a tool for managing, controlling and enabling networking and dynamics in VE integration.

This research makes two contributions: (1) to industry managers, it highlights the importance of dynamic organizational models, as the ultimate paradigm; and (2) to IS technologists: it alerts to the development of a new generation of electronic marketplaces, designated as market of resources, which supposedly should cope with the high reconfigurability of the VE model, at low transaction cost and preserving the firms' private knowledge.

\section{VIRTUAL ENTERPRISE RECONFIGURATION DYNAMICS AND BUSINESS ALIGNMENT}

For the last two decades, global competition has strengthened the significance of a company's ability to introduce new products, while responding to increasingly dynamic markets with customers rapidly changing needs, and thus claiming for shortening the time required to design, develop and manufacture, as well as for cost reduction and quality improvement. In the past a product could exist without great changes (adaptations, redesigns).

Reconfigurability, i.e., the ability of fast change face to the unpredictable changes in the environment (market), is a requirement of the VE to keep the partnership aligned with business requirements and is a consequence of product life cycle dynamics, i.e., business and market dynamics. This requirement implies the ability of (1) flexible and almost instantaneous access to the optimal resources to integrate in the enterprise; (2) design, negotiation, business management and manufacturing management functions independently from the physical barrier of space; and (3) minimisation of the reconfiguration or integration time.

Reconfiguration, meaning substitution of resources providers, generating a new instantiation of the network, can happen mainly from three reasons:

1. Reconfiguration during the network company life cycle is a consequence of the product redesign in the product life cycle, to keep the network aligned with the market requirements.

2. Reconfiguration as a consequence of the nature of the particular product life cycle phase (evolutionary phases).

3. Reconfiguration can happen also as a consequence of the evaluation of the resources performance during one instantiation of the network, or voluntarily by rescission of participating resources, wiling to disentail from the network.

VE dynamics considers a succession of network's states (physical configurations of the VE) along the time, i.e. the network reconfiguration dynamics. 
Dynamics means precisely the intensity of change the VE is subject of. A VE is defined as a reconfigurable network to assure permanent business alignment, in transition between states or instantiations (configurations) along time, (Figure 1).

In (Cunha \& Putnik, 2005a), the authors propose two parameters of Reconfigurability Dynamics: the number of requested reconfigurations per unit of time (Reconfiguration Request Frequency) and the time to reconfigure (Reconfiguration Time). Reconfigurability dynamics is directly proportional to the number of requests and inversely proportional to the time to make operational the reconfiguration (selection, negotiation and integration of resources in the VE). Reconfigurability Dynamics can be measured by a ratio between the frequency of reconfiguration requests and the reconfiguration time.

Ideally, reconfiguration time should tend to zero, and stable configuration durations should be dictated by business alignment needs, to keep VE performance at its maximum level. Due to reconfiguration cost and time, most of times dynamics is sacrificed by increasing the duration of stable and sometimes less performing configurations.

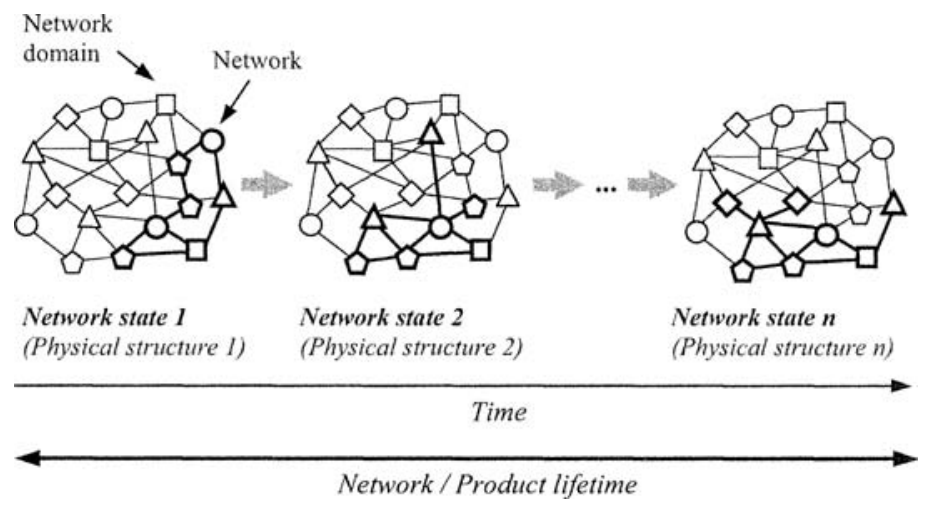

Figure 1 - Networking dynamics considers a succession of network's states along the time (Cunha \& Putnik, 2005a)

\section{NETWORKING AND DYNAMICS DISABLERS}

The main critical aspects associated to the recent concept of dynamically reconfigurable global networked structures, i.e., the main factors against networking and reconfigurability dynamics are (1) the reconfiguration costs and (2) the leakage of private information.

In an ideal business environment, a firm makes an informed assessment of the relevant costs, benefits and risks of outsourcing versus internal procurement. If there exists a profitable opportunity to outsource a service or operation, the client and the suppliers enter into a contract with a full knowledge of the nature of the work, signing a complete and explicit written agreement covering all aspects of the outsourced service and payments. But in most contractual relationships things do not happen this way. 
The costs of outsourcing are composed of both the explicit cost of carrying out the transaction as well as hidden costs due to coordination difficulties and contractual risks. The major costs associated with outsourcing include (1) the transaction costs and (2) the leakage of private information. In dynamic organisations, transaction costs are the firm reconfiguration costs, associated to partners search, selection, negotiation and integration as well as permanent monitoring and the evaluation of the partnership performance (Cunha \& Putnik, 2003b).

A firm's private information is information that no one else knows, and gives a firm an advantage in the market. Most of the times, this private information is a core competitive advantage that distinguishes a firm from its competitors. Networking or partitioning tasks between resources providers increases the risk of losing control of such type of information, which only through complete contractual agreements could be safeguarded, and furthermore, through an environment assuring trust and accomplishment of the duty of seal. The implementation of the networked structures requires tools to enable the preservation of the firm's knowledge. When considering dynamically reconfigurable networks, the risk of leakage of private information increases.

The implementation of the dynamic organisations requires the existence of tools and environments that, by reducing reconfiguration costs and reconfiguration time, overcome these two disabling factors, allowing dynamics as high as required to assure business alignment.

\section{RECONFIGURABILITY REQUIREMENTS}

The implementation of VE as a dynamic model requires that a number of functionalities (such as the summarized bellow) be assured.

- The permanent alignment of the VE with the market requirements can justify a dynamic process of the VE performance evaluation and the analysis of reconfiguration opportunities.

- Reduction of reconfiguration costs, which is based on the existence of computer aided tools and flexible and almost instantaneous access to the optimal resources to integrate in the enterprise, negotiation process between them, selection of the optimal combination and its integration.

- All must speak the same language. Search of potential resources providers, negotiation, etc, requires a specific and unambiguous resources representation language; ebXML and other XML standards allow communication; processes specification, of which RosettaNet is a good example are also indispensable; Webservices are becoming a core technology. However, an environment assuring knowledge-based support is indispensable, as the user (or the VE owner) will not be able to manage VE reconfiguration.

- The ability of identifying reconfiguration opportunities, either due to unaccomplishment from partners, or because alternative resources providers offering better solutions or prices are identified, is important to keep alignment with the market and simultaneously to assure an increased performance and competitiveness of the VE.

- The reduction of the time-to-contract and risk minimisation in a contractual agreement, which is a prerequisite for the VE model implementation. To 
reduce the contractualisation time, almost real-time contractualisation between the parties to integrate in the VE should be provided.

- The cost associated to the integration of an VE surpasses the sum of costs of making contacts, with the cost of overcoming distance, etc., it is also the opportunity cost because of taking a few more hours or days to locate resources or to reconfigure the VE. Speed is a fundamental characteristic, as one instantaneous physical structure (instance) of a VE may last only for a few days or even hours, so there it is necessary to act almost on real time.

- The ability to find the right potential partners to undertake further negotiation is essential. The domain for partners search should be large enough to provide good solutions.

\section{ENVIRONMENTS TO COPE WITH THE INTER- ORGANIZATIONAL DYNAMICS REQUIREMENT}

Value chains have been supported by a wide variety of technologies to communicate, but the pace of competition requires more intelligent and effective information and communication systems and technologies. Literature suggests that "traditional" Internet-based tools (such as WWW search engines, directories, e-mail, electronic marketplaces, etc.), can support some activities of VE integration, helping from procurement processes until the search of partners for a partnership, including electronic automated negotiation, electronic contracting, and market brokerage (Cunha \& Putnik, 2003a; Dai \& Kauffman, 2001; O'Sullivan, 1998; Wang, 2001).

Khalil and Wang (2002) have proposed ways for information technology to enable the VE model, by providing: (1) Web-based information systems, supporting B2B and B2C applications. (2) Sophisticated customer databases, supporting data mining, enhancing business intelligence and decision support. (3) Support for organizational learning (4) Groupware supported coordination and decision-making.

Several supporting infrastructures and applications must exist before we can take advantage of the VE organizational model, such as: electronic markets of resources providers, legal platforms, brokerage services, efficient and reliable global and intelligent information systems, electronic contractualisation and electronic negotiation systems, and decision support systems and tools.

To contribute to the reduction of search time in procurement and engineering, and to reduce transaction costs, manufacturers in several industries created electronic marketplaces, to pool their purchasing power and to develop technology platforms to exploit networked technologies. Electronic markets like Covisint (http://www.covisint.com) in the auto industry or Elemica in the chemicals (http://www.elemica.com) provide the environment to improve the VE dynamics.

In fact, several technologies and valuable applications have been developed that can support activities of the VE model, however, they do not cope with the requirements of the $\mathrm{VE}$ model, i.e., they do not implement the functionalities initially introduced and do not assure the high reconfigurability requirement.

\section{THE MARKET OF RESOURCES}

The Market of Resources (MR) is an institutionalised organisational framework and service assuring the accomplishment of the competitiveness requirements for $\mathrm{VE}$ 
dynamic integration and business alignment (Cunha \& Putnik, 2005b; Cunha, Putnik, Gunasekaran, \& Ávila, 2005). The operational aspect of the Market of Resources consists on an Internet-based intermediation service, mediating offer and demand of resources to dynamically integrate in a VE, assuring low transaction costs and reduced reconfiguration time (as demonstrated in (Cunha \& Putnik, 2003b, $2003 \mathrm{c})$ ) and the partners' knowledge preservation.

The service provided by the MR is supported by (Cunha \& Putnik, 2005b; Cunha et al., 2005):

- A knowledge base of resources and results of the integration of resources in previous VE,

- A normalized representation of information,

- Computer aided tools and algorithms,

- A brokerage service, and

- Regulation, i.e., management of negotiation and integration processes, as well as contract enforcement mechanisms.

The MR is able to offer (Cunha \& Putnik, 2005b):

- Knowledge for VE selection of resources, negotiation, and its integration;

- Specific functions of VE operation management; and

- Contracts and formalizing procedures to assure the accomplishment of commitments, responsibility, trust, and deontological aspects, envisaging that the integrated VE accomplishes its objectives of answering to a market opportunity.

\section{THE MARKET OF RESOURCES AS AN ENABLER OF RECONFIGURATION DYNAMICS}

This section summarises some of the results of the validation of the Market of Resources using a cost and effort model specifically developed based on a demonstrator to simulate the MR performance, and its comparison with the utilisation of "traditional" Internet-based techniques ( $W W W$ search engines, $W W W$ directories and e-mail) to support search, negotiation and selection of a set of resources providers to integrate or reconfigure a VE. These simulations were based on cost and effort models respectively for the MR and for the "traditional" Internetbased techniques. The cost and effort models, as well as results and discussion of this validation can be found in (Cunha \& Putnik, 2003b, 2003c, 2006).

Consider $\mathrm{K}$ to be the number of required resources to integrate in a VE project (creation or reconfiguration). Figure 2 represents search and selection time (in minutes) corresponding to $\mathrm{K}=2, \mathrm{~K}=3$ and $\mathrm{K}=5$, using the Market of Resources (represented by the line labelled "Market" in the legend of the figure) and using traditional internet-based technologies (the line labelled "Trad" in the legend of the figure), in function of the search domain dimension. A similar simulation was also undertaken to estimate cost instead of time.

For example, using the MR, it is possible to search, negotiate, contactualise a Virtual Enterprise creation/reconfiguration, for $\mathrm{K}=3$ and an average search domain of 150 potential resources providers in around five hours. For the same situation, the value offered by the "traditional" Internet-based tools is ten times longer.

Based on analytical simulation results based on the already mentioned cost and effort models, the authors identified the domain of opportunities for the MR, in 
function of the number of required resources $(\mathrm{K})$ and of the search domain dimension (Figure 3). The figure identifies the region where the Market of Resources presents increased efficiency when compared with the traditional Internet-based technologies, in function of the number of required resources $(K)$ and the search domain dimension, considering time and cost parameters. Considering the time parameter, the MR reveals increased efficiency in almost all the situations (see the "Time line" in Figure 3).

The MR demonstrated increased efficiency in coping with complex products (especially $\mathrm{K}>=3$ ) and increasing with the solution space dimension.

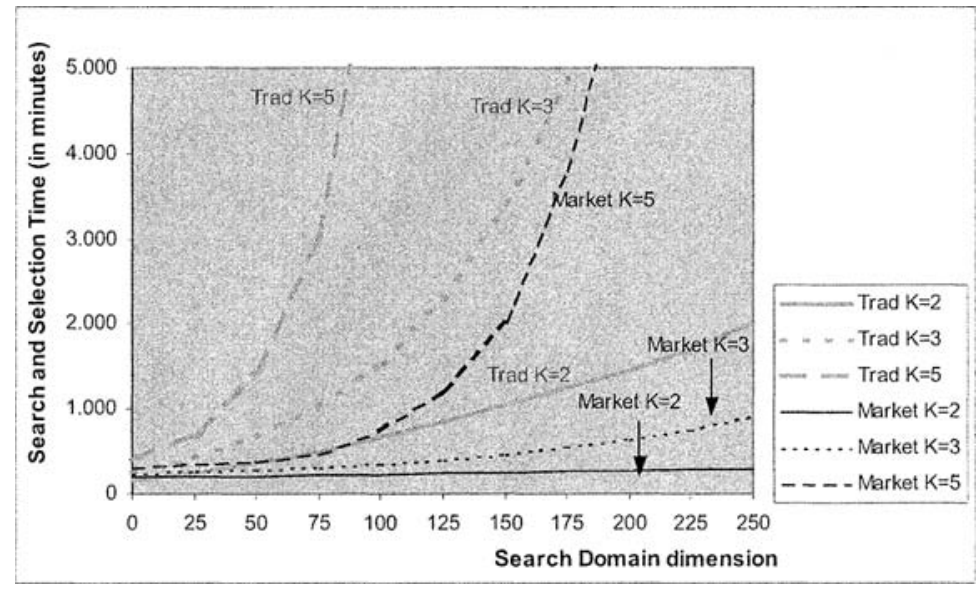

Figure 2 - Search and Selection Time (in minutes) in function of the Search Domain dimension, for different situations of the number of required resources $(\mathrm{K})$

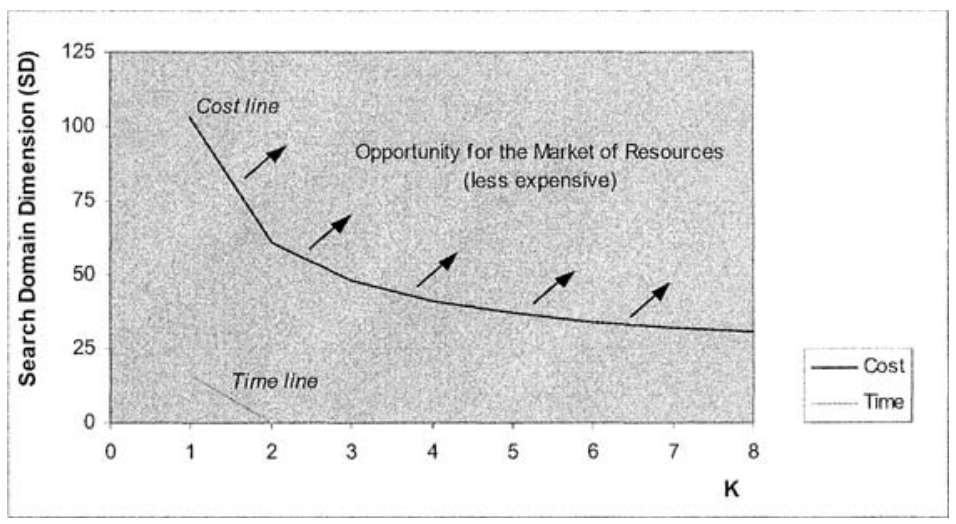

Figure 3 - Break-even points based on search and selection cost and time 


\section{CONCLUSIONS}

The Market of Resources revealed the ability to support higher reconfiguration requirements than the traditional tools (due to the more reduced reconfiguration time and cost it allows) and its suitability increases with product complexity (here traduced by the number of required resources, K). Traditional tools only support simple products (one at each time) and do no support dynamics.

By reducing reconfiguration time and cost, the $M R$ is an enabler of reconfiguration dynamics, an enabler of dynamic organizational models as the VE one. Obviously, dynamic organisational models are not general and "all-purpose" solutions. This model represents and adequate solution for highly customised products, with small series, in highly competitive and changing environments where permanent business alignment is crucial, i.e., situations where partnership stability is low (sometimes very low), dependency between partners is very weak and reconfiguration dynamics should be as high as possible, given the permanent monitoring of the structure to traduce the most competitive solution at every moment of the product life cycle.

\section{REFERENCES}

1. Cunha, M. M., \& Putnik, G. D. (2003a). Agile/Virtual Enterprise Enablers: a comparative analysis. In D. N. Sormaz \& G. A. Süer (Eds.), Proceedings of Group Technology/Cellular Manufacturing World Sympositm 2003 (pp. 243-247). Columbus, Ohio, USA: Ohio University.

2. Cunha, M. M., \& Putnik, G. D. (2003b). Market of Resources versus e-Based Traditional Virtual Enterprise Integration - Part I: A cost model definition. In G. D. Putnik \& A. Gunasekaran (Eds.), Proceedings of the First International Conference on Performance Measures, Benchmarking and Best Practices in New Economy (pp. 664-669). Guimaràes, Portugal (June, 10-13): University of Minho.

3. Cunha, M. M., \& Putnik, G. D. (2003c). Market of Resources versus e-Based Traditional Virtual Enterprise Integration - Part II: A comparative cost analysis. In G. D. Putnik \& A. Gunasekaran (Eds.), Proceedings of the First International Conference on Performance Mecisures, Benchmarking and Best Practices in New Economy (pp. 667-675). Guimarães, Portugal (June, 10-13): University of Minho.

4. Cunha, M. M., \& Putnik, G. D. (2005a). Business Alignment Requirements and Dynamic Organizations. In G. D. Putnik \& M. M. Cunha (Eds.), Virtual Enterprise Integration: Technological and Organizational Perspectives (pp. 78-101). London: Idea Group Publishing.

5. Cunha, M. M., \& Putnik, G. D. (2005b). Market of Resources for Agile/Virtual Enterprise Integration. In M. Khosrow-Pour (Ed.), Encyclopedia of Information Science and Technology (pp. 1891-1898). Hershey, PA: Idea-Group Publisher.

6. Cunha, M. M., Putnik, G. D., Gunasekaran, A., \& Ávila, P. (2005). Market of Resources as a Virtual Enterprise Integration Enabler. In G. D. Putnik \& M. M. Cunha (Eds.), Virtual Enterprise Integration: Technological and Organizational Perspectives (pp. 145-165). London: Idea Group Publishing.

7. Cunha, M. M., \& Putnik, G. D. (2006). Identification of the domain of opportunities for a market of resources for virtual enterprise integration, International Journal of Production Research, Vol. 44, No. 12, June 2006, pp. 2277-2298. Taylor \& Francis

8. Dai, Q., \& Kauffman, R. (2001). Business Models for Internet-Based E-Procurement Systems and $B 2 B$ Electronic Markets: An Exploratory Assessment. Paper presented at the 34th Hawaii International Conference on Systems Science, Maui, HI.

9. Khalil, O., \& Wang, S. (2002). Information Technology Enabled Meta-Management for Virtual Organizations. International Jounal of Production Economics, 75(1), 127-134.

10. O'Sullivan, D. (1998). Communications Technologies for the Extended Enterprise. Int. Jounal of Production Plaming and Control, 9(8), 742-753.

11. Wang, C. X. (2001). Supply Chain Coordination in B2B Flectronic Markets, Proceedings of the 32nd Anmal Meeting of the Decision Sciences Institute. San Francisco, CA. 